\title{
Evaluation of the Ryegrass Stem Rust Model STEMRUST_G and Its Implementation as a Decision Aid
}

\author{
W. F. Pfender, L. B. Coop, S. G. Seguin, M. E. Mellbye, G. A. Gingrich, and T. B. Silberstein
}

United States Department of Agriculture-Agricultural Research Service National Forage Seed Production Research Center and Oregon State University Departments of Crop Science and Botany and Plant Pathology, 3450 SW Campus Way, Corvallis 97331. Accepted for publication 24 July 2014

\section{ABSTRACT}

Pfender, W. F., Coop, L. B., Seguin, S. G., Mellbye, M. E., Gingrich, G. A., and Silberstein, T. B. 2015. Evaluation of the ryegrass stem rust model STEMRUST_G and its implementation as a decision aid. Phytopathology 105:35-44.

STEMRUST_G, a simulation model for epidemics of stem rust in perennial ryegrass grown to maturity as a seed crop, was validated for use as a heuristic tool and as a decision aid for disease management with fungicides. Multistage validation had been used in model creation by incorporating previously validated submodels for infection, latent period duration, sporulation, fungicide effects, and plant growth. Validation of the complete model was by comparison of model output with observed disease severities in 35 epidemics at nine location-years in the Pacific Northwest of the United States. We judge the model acceptable for its purposes, based on several tests. Graphs of modeled disease progress were generally congruent with plotted disease severity observations. There was negligible average bias in the 570 modeled-versus-observed comparisons across all data, although there was large variance in size of the deviances. Modeled severities were accurate in $>80 \%$ of the compari- sons, where accuracy is defined as the modeled value being within twice the $95 \%$ confidence interval of the observed value, within \pm 1 day of the observation date. An interactive website was created to produce disease estimates by running STEMRUST_G with user-supplied disease scouting information and automated daily weather data inputs from field sites. The model and decision aid supplement disease managers' information by estimating the level of latent (invisible) and expressed disease since the last scouting observation, given season-long weather conditions up to the present, and it estimates effects of fungicides on epidemic development. In additional large-plot experiments conducted in grower fields, the decision aid produced disease management outcomes (management cost and seed yield) as good as or better than the growers' standard practice. In future, STEMRUST_G could be modified to create similar models and decision aids for stem rust of wheat and barley, after additional experiments to determine appropriate parameters for the disease in these smallgrain hosts.

Additional keywords: Lolium perenne, model validation, Puccinia graminis subsp. graminicola.
The simulation model for stem rust epidemics in perennial ryegrass, described in the accompanying article (25), was constructed with the goal of improving disease management through education and decision support. Fungicides to control stem rust caused by Puccinia graminis subsp. graminicola represent the largest expenses for disease control in seed crops of perennial ryegrass (Lolium perenne) in some of the world's major seed production regions, such as the Pacific Northwest of the United States (37). Stem rust epidemic severity and, thus, the need for fungicides can differ dramatically from year to year and from field to field within a year. Because of this unpredictability of stem rust epidemic severity, and because the disease is capable of causing severe yield loss in the perennial ryegrass seed crop (21), a management decision aid for fungicide application would be useful.

The intended uses of the epidemic model STEMRUST_G (25) are heuristic as well as pragmatic. When implemented in a form that allows users to visualize the effects of various inputs (weather conditions, fungicide applications, and initial disease levels) on epidemic development, the model can serve as a tool to learn about the biology and behavior of stem rust epidemics. In practical use, the model can be combined with information about

Corresponding author: W. F. Pfender; E-mail address: pfenderw@onid.orst.edu

http://dx.doi.org/10.1094/PHYTO-06-14-0156-R

This article is in the public domain and not copyrightable. It may be freely reprinted with customary crediting of the source. The American Phytopathological Society, 2015 the damage threshold (21) and implemented as a decision aid for fungicide application. The model's value for either use depends on how well its output corresponds with actual dynamics of the epidemic and, therefore, it is necessary to evaluate the performance of the model.

Model evaluation is a multifaceted concept. Rykiel (28) presents a thorough treatment of the subject, including historical development of approaches and philosophy. He notes that a model can be evaluated for its intrinsic logic ("verification"), agreement between modeled biological parameters and observed phenomena ("calibration"), sufficiently accurate behavior of the model ("validation"), confidence in its application to real situations ("credibility"), and applicability over geographical or other domains ("qualification") (28). A key point regarding validation is that there is no objective standard for the criterion of the model being "sufficiently accurate for its purposes". The standard must depend on the intended use of the model as well as on the statistical behavior of the real system being modeled. It is noted that data are not necessarily an infallible standard for judging model performance, because the obtainable data may be wanting in accuracy or precision (28). Various procedures have been proposed for the validation process (29). These include "subjective" evaluation by visual assessment of graphed results, "event validity" for modeled versus observed outcomes with respect to timing and magnitude, "multistage validation" in which subprocesses of the overall model are individually validated, and "statistical validation" to compare statistical properties of the model output and the real system. Most researchers agree that the model should be validated against data that were not used in 
model calibration (11). Rykiel (28) notes that a model is an analogy, not a complete representation, and that metrics of its validity should depend on the purpose of the model, criteria for acceptability, and context for its use rather than on its ability to quantify in detail all aspects of the biological process.

In most published validations of simulation models for plant disease epidemics $(1,4,7,26,30,31,34)$, a combination of subjective (graphical representation) and statistical methods was used. The statistical methods comparing modeled and observed outcomes included analysis of epidemic rate (1), area under the disease progress curve (AUDPC) (4), timing of benchmark disease severities (31), and direct comparison of observed versus modeled values $(7,26,34)$. The statistical assessment typically was based on a predefined but nonstandard level of acceptable deviation deemed appropriate to the intended use of the model (4). For a late blight model that was reparameterized for use in a geographical area different from its original range (3), a specific study was done to qualify for model for use in the new area (2). The usual combination of subjective and statistical validation has been applied to the few simulation models previously published for rust diseases of graminaceous plants $(26,34)$.

One important application for plant disease epidemic models is in decision aids for disease management $(9,14,15)$. Historical progress in decision aid implementation has been driven, in large part, by technology for collecting data and disseminating information. The earliest plant disease decision aid implementations, such as the first potato late blight decision aids (13), made use of manually read data loggers for data collection and the telephone for notification. An era of on-farm weather stations, bio-accumulators, and coupled models on personal computers began in the 1980 s and continues today $(10,33)$. Another approach is the use of a network of sentinel sites in crop fields from which weather and disease data are disseminated by publicly led sources $(8,16,32)$ or private companies $(27,35)$. Since the Internet era began in the 1990s, the standard has been Internet-accessible interactive websites, where incoming weather data drives models that are initialized by users' selected inputs $(5,12,38)$.

The objectives of the work described in this article were to (i) validate the STEMRUST_G model (25) for its use in representing the behavior of stem rust epidemics in perennial ryegrass seed crops and as a decision aid effective for managing the disease and (ii) produce an interactive website to deliver decision aid information to disease managers.

\section{MATERIALS AND METHODS}

Field observations of stem rust epidemics. The stem rust severity data to be used in validating the epidemic model were collected from 35 epidemics observed in replicated field plots of perennial ryegrass in experiments conducted from 1999 to 2004 and 2006 to 2007. In 1999 to 2004, the observations were made in experiments conducted at the Hyslop experiment farm near Corvallis, OR. The data of 1999 to 2004 were from 26 observed epidemics that were not used in model development (25). The plots were planted in autumn with seed of perennial ryegrass ('Morningstar', moderately susceptible) in rows $30 \mathrm{~cm}$ apart. Experiments were conducted the following summer (first-year plantings) or in the second summer (second-year plantings). The seed crop reaches maturity and is harvested in early to mid-July. Individual plots were mostly 4.2 by 7.5 or $16 \mathrm{~m}$ in size, and there were three to five replicate plots per treatment, arranged in a balanced randomized complete block design and separated from one another by at least $6 \mathrm{~m}$. Treatments were defined by fungicide application (fungicide type and timing, including nontreated) and stand age. For purposes of validation, the season-long disease development in each replicated treatment was considered an epidemic. Fungicides were applied with mechanized equipment at labeled rates: propiconazole at $184 \mathrm{~g}$ active ingredient (a.i.)/acre as Tilt, azoxystrobin at $150 \mathrm{~g}$ a.i./acre as Quadris, or a mixture of propiconazole and azoxystrobin at 185 and $111 \mathrm{~g}$ a.i./acre, respectively, as Quilt (all fungicides manufactured by Syngenta Inc., Basel, Switzerland). In 2006 and 2007, data were obtained from replicated-plot experiments in grower fields. In these experiments (nine epidemics) there were three replicate plots ( 8 by 80 or $135 \mathrm{~m}$ ) per treatment, and the perennial ryegrass cultivars were 'OS' in 2006 and 'VNS' in 2007. Fungicide application was as described. Stem rust epidemics developed from natural inoculum in all experiments (1999 to 2007); therefore, there was considerable variation in epidemic severity among years.

Disease severity assessment was at 1- to 3-week intervals, as described previously $(21,25)$. Early-season assessments were made by counting pustules in randomly selected $15-\mathrm{cm}$ lengths of row, 5 to 10 samples per plot. Starting in late April, when the canopy closed, disease severity was sampled by counting pustules in 5 to 10 randomly placed quadrats $(15$ by $15 \mathrm{~cm})$ per plot. As previously noted (25), there is a logistical constraint on counting all pustules through the full canopy depth when significant growth has occurred; therefore, a conversion algorithm (25) was employed to estimate total disease from disease observed in the quadrat. The observations of the 5 to 10 samples per plot were averaged to produce the replicate-plot value for the sampling date. No attempt was made to account for spatial distribution of the disease within a plot. In the experiment-farm plots (1999 to 2004), access to the plots was by a movable platform suspended above plants, thus minimizing disturbance of epidemic progress that would result from an observer entering the plots. In the growerfield experiments (2006 and 2007), the plots, which were much larger, had to be entered by the observer. In all years, for each sampling date and each treatment, the three to five replicate-plot observations were used to calculate the average severity and the 95\% confidence interval (CI) of that value. A disease progress curve was constructed for each treatment (average severity versus time). The AUDPC was expressed as percentage of the healthy crop area duration (36) for the 3-week critical period midway between anthesis and seed maturity (21).

Weather data. Each year at the field sites, weather data (air temperature and leaf wetness at canopy height, rainfall, and relative humidity at $1.5 \mathrm{~m}$ above the ground) were measured at 15-min intervals by means an automated weather station (Campbell Scientific Inc., Logan, UT). Technical details of the sensors, their placement, and the recording equipment are provided in a subsequent paragraph. Each weather station was equipped also with communications gear automated for daily transmission of the collected data to a base station computer for convenient access and further processing. The weather data were used to calculate a daily value for infection favorability of the weather (18) as well as daily accumulation of heat units for calculating predicted development of plant and pathogen $(17,25)$.

Model runs. This article describes validation experiments for STEMRUST_G, the simulation model for perennial ryegrass stem rust (25). The perl code for STEMRUST_G, as well as accompanying files of documentation and example datasets, are available for download from the grass stem rust estimator website (http://pnwpest.org/cgi-bin/stemrust1.pl).

Output of STEMRUST_G was produced for each epidemic to compare with the actual disease severity observed at various times during the season. Each model run used the weather input (.ril file) (25) created from data obtained at the site and year of the epidemic; the plant phenology biofix input (date of flag sheath appearance) (25) was observed directly. Observational sampling error at very low disease levels rendered such observations unreliable; therefore, model runs were conducted only for initial values $>1$ pustule (average) per $900-\mathrm{cm}^{2}$ quadrat. Several model runs were conducted for each epidemic, one run starting for each observation date at its observed disease level (25). In this way, the output for each of the runs included daily disease severity values 
for all observation dates subsequent to the run initialization date. For example, an epidemic with six observation dates would have five model runs: the run initialized on observation date 1 would produce output to include disease severities for dates 2 through 6 , the run initialized on date 2 would produce output for dates 3 through 6 , and so on. Under the definitions and operation of the model, "observed" disease represents active (living) pustules. The fungicides kill a proportion of existing pustules $(20,22)$ but their appearance remains similar to that of living pustules for several days, during which time the two classes are nearly indistinguishable. Therefore, we applied a rule to add modeled fungicide-killed pustules to the modeled living pustules for dates $\leq 5$ days after a fungicide application. AUDPC for the yield-critical 3-week time window, centered between anthesis and harvest (21), was calculated for each run. Modeled disease area as a proportion of modeled plant area was integrated across this time window to produce AUDPC expressed as percentage of healthy area duration (36).

Analysis for model validation. Because a stem rust epidemic may encompass observed disease severities ranging over four to six orders of magnitude, all data were converted to $\log _{10}$ values before graphing (Fig. 1) and analysis. Several procedures were used to compare observed disease severity with modeled severity for each observation date. A subjective (29) evaluation for the congruence of model output with observed values was conducted by visual examination of graphs. Epidemics were selected for graphing based on results of quantitative tests for accuracy described later in this section. For each of the nine location-years, the three epidemics for which the model gave the most accurate, the least accurate, and intermediately accurate representation, respectively, were evaluated.

Overall bias of the model in representing observed data was evaluated as the deviation in disease severity (modeled minus observed) averaged across all data points We also plotted each deviation against the time interval between the model run initiation date and the comparison date. To score accuracy of the model, we assessed whether or not the modeled value for disease severity on a given day was within a predefined tolerance of the observed severity. We took the $95 \%$ CI of each observation to represent the range of its true value, then chose a twofold difference as an acceptable tolerance, further allowing the modeled value to fall within this envelope $(2 \times$ the $95 \% \mathrm{CI})$ within \pm 1 day of the observation-value date. Because all data analysis was conducted on $\log _{10}$ values, doubling the $95 \%$ CI was done by adding 0.3 to its computed value. A binary assessment (accurate or not by the tolerance criterion) was assigned to the modeledversus-observed comparison for each data point. Each comparison was also classified according to the time interval between model initialization day and target comparison day. Our criterion for validation of the model with respect to accuracy of predicted severity was that $\geq 75 \%$ of modeled severity points should be accurate for model runs initiated up to 2 weeks prior to the target date, a reasonable amount of time for crop advisors to take a management decision. In addition to bias and accuracy assessment, we compared modeled versus observed critical-period AUDPC for model runs initiated at the beginning of the critical period as well as at 1 and 2 weeks prior to the critical period. The AUDPC were plotted (modeled versus observed), and also classified in a two-by-two contingency table of less than or greater than the damage threshold $(2 \%$ reduction in healthy area over the critical period) (21) for modeled and observed. As a point of qualification, we compared the deviation (modeled minus observed) in the training data set with that in the validation data set, which included a larger range of years and some additional locations and cultivars. We also compared the modeledminus-observed deviation in the epidemics monitored at the experiment farm (1999 to 2004) with those in grower fields (2006 and 2007).
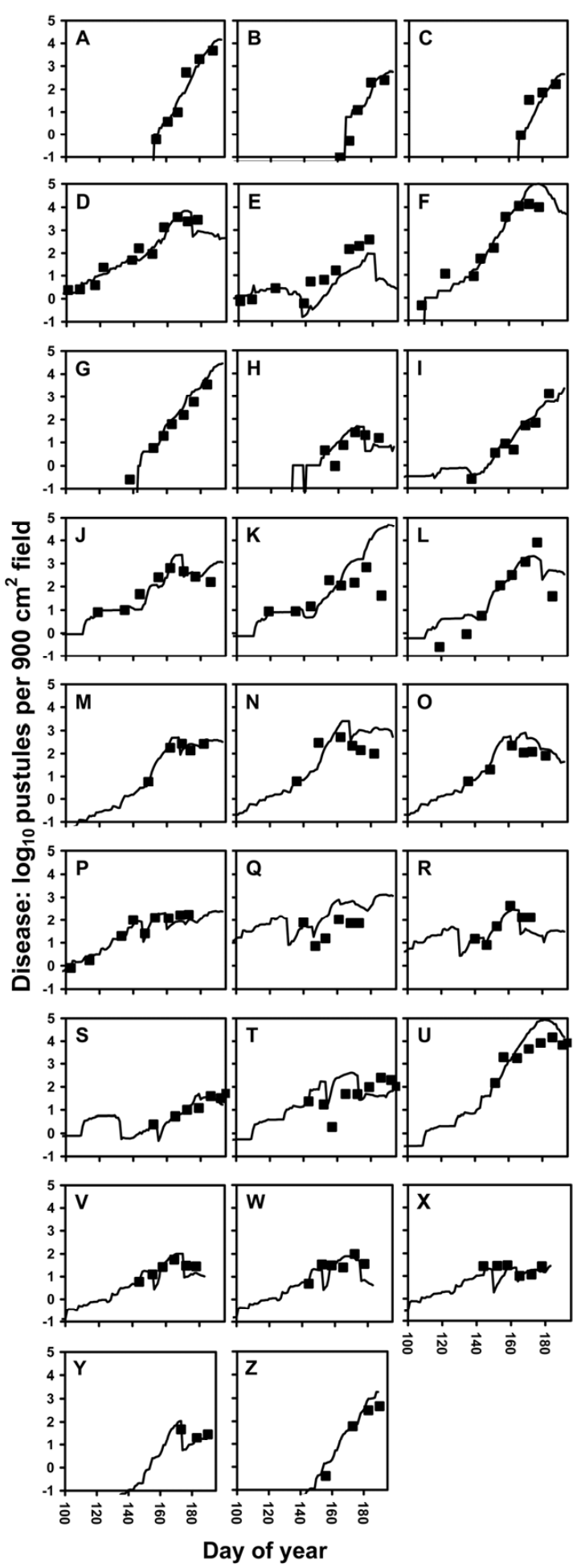

Fig. 1. Modeled (solid line) and observed (squares) disease severity for selected epidemics of perennial ryegrass stem rust in nine location-years. Each disease progress curve was produced by the simulation model STEMRUST_G initialized with the season's first observed value $>1$ pustule per $900 \mathrm{~cm}^{2}$, and run with inputs of the site's season-long weather data and fungicide applications (if any). For each location-year (row), three epidemics were selected to display that location-year's most accurately modeled epidemic (left column), least accurately modeled epidemic (center column), and an epidemic with intermediate model accuracy (right column). Epidemic location-years are Hyslop experiment farm in A to C, 1999; D to F, 2000; $\mathbf{G}$ to I, 2001; J to $\mathbf{L}$, 2002; $\mathbf{M}$ to O, 2003; and $\mathbf{P}$ to $\mathbf{R}, 2004$ and grower fields in $\mathbf{S}$ to $\mathbf{U}, 2006$ (GF_Sp06); V to X, 2007 (GF_Sh07); and Y to Z, 2007 (GF_Jc07). Accuracy classes are based on proportion of modeled values that fell within twice the 95\% confidence interval of observed values: most accurate (A, D, G, J, M, P, $\mathrm{S}, \mathrm{V}$, and Y), least accurate (B, E, H, K, N, Q, T, W, and Z), and intermediate accuracy (C, F, I, L, O, R, U, and X). 
Interactive website decision aid. A decision aid for fungicide application to manage perennial ryegrass stem rust was constructed as an Internet website. Requirements for the website were (i) collection and transmission of weather data from field locations to a server, where it can be used as input to drive STEMRUST_G, and (ii) creation of an interactive webpage, where users can supply required information about their crop and visualize the resultant output of the model displayed in a context of useful information.

Weather data were collected by automated weather stations located in grass seed fields of western Oregon's Willamette Valley, where almost all the region's grass seed production is centered. Equipment manufactured by Campbell Scientific Inc. was used in all years and, in some years, there were also fields monitored with equipment produced by Adcon USA (Davis, CA). Data, collected at 15- or 30-min intervals, included air temperature and leaf wetness at canopy height, as well as rainfall, air temperature, and relative humidity at $1.5 \mathrm{~m}$ above the ground. Air temperature was measured with a thermistor probe mounted in a vaned shield. Leaf wetness was measured with a painted, flatplate resistance grid mounted at a $45^{\circ}$ angle facing west (18). In most installations, there were two air temperature probes (for redundancy and quality control assessment) and two leaf wetness sensors. If data from both leaf wetness sensors looked plausible (characteristic diurnal variation), a sampling interval was classed as wet if either of the sensors indicated wetness. Each morning, the datalogger program calculated the overnight infection-favorability value (a temperature and leaf-wetness algorithm) (18). Data from each field location were transmitted daily at 10 a.m. by cell phone (for Campbell Scientific weather stations) or radio (for Adcon stations). The information was routed to the base-station server where the code for STEMRUST_G and the website interface resided. On the server was a script to read the field data file and transform it into the weather input file needed to run STEMRUST_G. This input file (.ril file) (25) has one line of data for each day, with columns (daily entries) for rainfall, cumulative heat units (17), and favorability of weather for infection (18) calculated from the field weather data. There were at least 3 and as many as 12 weather stations in operation in different years. In every year, there was a station at the Hyslop experiment farm near Corvallis, as well as a station in the north part of the Willamette Valley and another in the higher-elevation region in the foothills of the Cascade Mountains. In most years, there was a station near the south end of the valley. When funds were available for additional stations, they were placed to balance extent and intensity of geographic coverage for the grass seed production area.

The website interface was written in HTML and Javascript (on the client side), and Perl (on the server side). The interface was written to display model inputs and results on the same page, to simplify presentation and to encourage "gaming" or changing inputs to discover effects on the outputs. It has a drop-down menu to select the geographic source (weather station location) of the weather data to be used in running STEMRUST_G. The user enters the observed disease severity obtained by scouting the field. Disease severity, with observation date, can be entered as number of pustules per unit length of row or number of pustules per 10 grass tillers. There is information in a text box, as well as a link to photographs, to guide collection of the disease severity information. The user also enters a plant phenology date (or lets the program provide a default value). For fungicide applications that have taken place, the user can enter the fungicide type (triazole, strobilurin, or the mixture of these two) and date for up to five applications. The model assumes that these applications are at full labeled rate. A box in the center of the page is populated with text providing help information when the cursor is positioned at a corresponding part of the webpage. After the user clicks the "compute" button, a graph is populated with output from STEMRUST_G run with the inputs (weather data, scouting observations, and fungicide history) that the user has selected and provided. The graph plots rust population ( $\log _{10}$ [pustules per $30 \mathrm{~cm}$ of row]) versus date, with separate lines for visible disease and for total infections (visible pustules plus latent infections). The graph has an empirically estimated action threshold line that can be compared with the line representing total infections to indicate the need for fungicide application (25). The same figure also displays each day's "infection value", the conduciveness of the weather to infection. The design and operation of the webpage allows the user to see the results of STEMRUST_G run for any current or past-year (archived) weather dataset, with any chosen disease severity input and fungicide history. Interpretation of graphed results is left to the user's discretion. As explained in one of the website help messages, if the total active infections line crosses above the action threshold line, then the need for additional fungicide treatment is implied but not stated explicitly. No forecasted weather data, either as a real-time forecast or as historical normal data, are provided in the current version to allow predicting future stem rust activity.

Field performance of decision aid. A pragmatic test of the STEMRUST_G-based decision aid was conducted as large-plot tests in grower fields over the course of 5 years (2004 to 2008) at two locations in western Oregon each year ( 3 of the 10 locationyears were also included in the model validation procedures described in previous paragraphs). The fields were perennial ryegrass grown for seed under standard production practices. There were eight different cultivars represented among the 10 fields, and 9 of them were in their first year of production. Experiments were arranged in randomized complete block design, with three replicate plots per treatment; individual plot size was 8 by 80 to $125 \mathrm{~m}$. A weather station was installed at each site, with communications gear to provide daily data transmission. STEMRUST_G was run with the weather data, plant phenology biofix, and disease scouting data from each site. One treatment at each site received fungicide applications as indicated by the STEMRUST_G decision aid; that is, whenever the model output for total disease (latent plus erumpent) reached the action threshold for the fungicide to be used. Fungicide choice was based principally on plant phenology: a strobilurin-containing material was used if an application was made during active tiller elongation (due to its superior activity against sheath-to-culm disease transmission) $(19,20)$, whereas propiconazole alone typically was used for applications before or after this developmental stage. In accordance with the fungicide label, the strobilurin-containing material was not used more than twice during the season on a given field. Another treatment at each site received fungicide applications according to "standard practices" (i.e., whenever the grower made fungicide application to the remainder of the field in which the plots were located). The fungicides and their application methods were as described in a preceding paragraph. There was one, nonreplicated plot at each location in which no fungicides were applied. This nontreated check was not used in analysis of variance or mean separation calculations but served as an indicator of ambient epidemic severity for each location-year. Plots were harvested at maturity with commercial equipment. For each plot, total harvested seed weight was determined and a subsample was analyzed for percent cleanout (percentage of the harvested weight remaining as marketable seed after standard cleaning procedures). The calculated clean-seed weight per plot was used as the value for statistical analysis. For experiments with a statistically significant difference in seed yield between the standard and decision-aid treatments, the difference was multiplied by the farm-gate price per kilogram of seed to calculate treatment effect on value of the harvested seed. Economic benefit of the decision aid was evaluated as difference in economic return between the standard-practice and decision-aid managed treatments. Return was calculated as value of harvested seed minus cost of fungicide treatments. 


\section{RESULTS}

In most of the 35 data sets for epidemics of stem rust of perennial ryegrass, STEMRUST_G performed well as judged by conformance of the model estimates to the general shape and position of the observed-data epidemic curves ("subjective validation") (29). Modeled and observed disease values for epidemics in nine location-years are displayed in Figure 1, including many in which fungicides were applied as well as some that were nontreated. The individual epidemics illustrated in this figure were selected for display based on deviation of modeled versus observed values. For each location-year, the data set with the greatest overall model accuracy (observed versus modeled) is shown in the left column, the data set with the poorest model accuracy is in the middle column, and a data set with an intermediate accuracy is in the right column. Accuracy level had been determined as in Figure 2B. Among the 26 graphs of Figure 1, the disease progress curve produced by the model is, by visual assessment, generally near the observed data points in 20 graphs, whereas the similarity between modeled and observed is poor in 4 (Fig. 1E, K, N, and Q) and marginally acceptable in 2 (Fig. 1T and U). It should be noted that the shape of each curve is determined by the fullseason weather data and the fungicide applications. Therefore, the model output curves of various initiation dates within one location-year would be parallel but pass through the observeddata point for which the run is initiated (25) (see Fig. 3B in literature citation 25).

The bias in the model can be evaluated by calculating the deviance between modeled and observed values for time points subsequent to model initiation. Averaged across all comparisons (all data points in all epidemics, $n=570$ ), the mean of the error was $0.07 \log$ units (i.e., a multiplicative factor of 1.15). We also plotted average bias as a function of the time between model initialization date (run initialized with disease severity observed on that day) and date for which the model output is compared with the observed value. This time interval we designate the "initialization-to-comparison" time interval. Deviations are plotted against initialization-to-comparison time interval for the 26 epidemics at the experiment farm (Fig. 3A), the 9 epidemics in grower fields (Fig. 3B), or all epidemics combined (Fig. 3C). Linear regression lines show the relationship between bias and number of days elapsed from model initiation date to comparison date. In all epidemics, the bias approaches zero as the time interval decreases to the shortest time interval assessed (5 days) and, even at an initialization-to-comparison of 50 days, the mean bias over all data sets is quite low $\left(<0.2 \log _{10}\right.$ units) (Fig. 3C). Bias in modeled epidemics for the grower fields (Fig. 3B) was no greater than that for the epidemics monitored at the experiment farm (Fig. 3A). Despite the good performance of the model indicated by its negligible bias, there was substantial variance in the deviance between modeled and observed values. In all, $\approx 10 \%$ of the 570 individual comparisons had deviances $>1.0$ (log units), and $2 \%$ were $>1.5$ (Fig. 3C). However, $73 \%$ of the deviances (one standard deviation) were $<0.6$ (log units, equal to a fourfold difference), and $42 \%$ were $<0.3$ (twofold difference).

Each comparison of modeled and observed disease values also was classified as "accurate" or "inaccurate", according to whether or not the modeled value was within our predetermined acceptance envelope. This envelope is the range of values twice the $95 \%$ CI of the particular observed value, within \pm 1 day of the comparison date. Of the 570 modeled versus observed comparisons in all epidemics, $81 \%$ were within the acceptable accuracy range. For comparisons in which the initialization-to-comparison interval was $\leq 14$ days, $85 \%$ were in the acceptable range. Accuracy scores also were tallied within location-years (Fig. 2A) and within individual epidemics (Fig. 2B). In eight of the nine location-years, the model output met or exceeded the criterion of $75 \%$ accuracy for points with initialization-to-comparison inter- vals $\leq 14$ days (Fig. 2A). Accuracy of the model when assessed by individual experiment (Fig. 2B) ranged from 33 to $100 \%$ and was at or above $75 \%$ for 25 of the 35 experiments. These by-experiment accuracy rates were the criteria used to select the poorest-, highest-, and intermediate-accuracy individual epidemics in each location-year for display in Figure 1.

We also compared the observed and modeled AUDPCs of each epidemic. Disease severity was calculated as percentage of the possible healthy area duration (HAD) (36) during the 3-week time interval centered between anthesis and harvest. We previously determined this interval to be the critical time window for predicting rust-related reduction in seed yield (21). The modeled values used in this comparison were obtained for model runs initiated at the beginning of the critical window, and also for runs initiated 1 and 2 weeks prior to that date; some epidemics did not have observed disease early enough in the season to initiate the model at 2 or 1 weeks prior to the critical window. Observed AUDPC were categorized as damaging (AUDPC $\geq 2 \%$ HAD) or nondamaging (AUDPC $<2 \%$ HAD), in reference to the damage threshold determined previously (21). In all, there were 86 comparisons and the model was correct in 80 (69 correctly modeled to
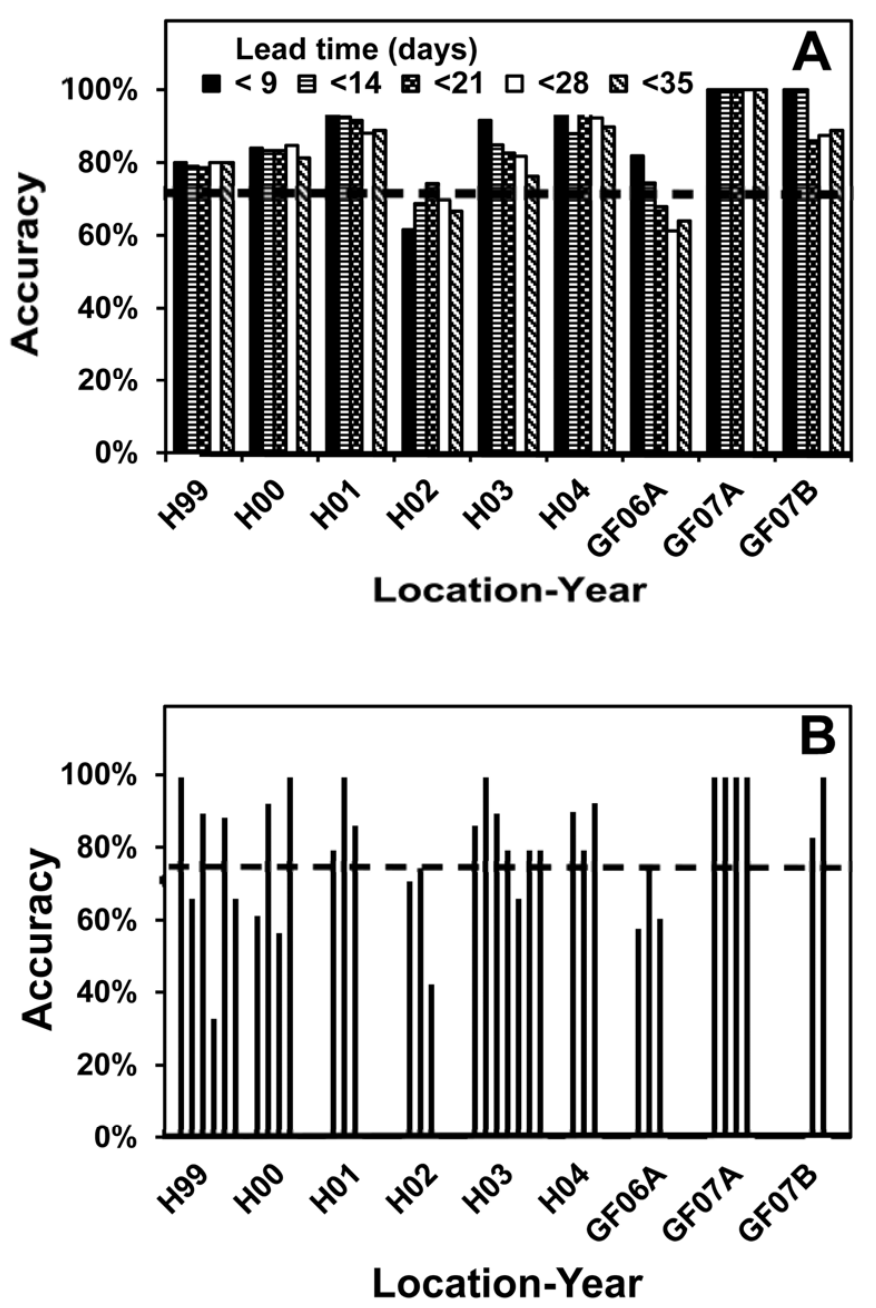

Fig. 2. Accuracy of stem rust model output, calculated as proportion of comparisons (modeled versus observed) in which the modeled severity fell within twice the $95 \%$ confidence interval of the observed severity within \pm 1 day of the observation date. Dashed line is $75 \%$ accuracy level. A, Accuracy results grouped by location-year ( $\mathrm{H} 99, \mathrm{H} 00$, and so on) and time interval (days) between initialization date of the model run and date of the observation for which accuracy is determined. B, Overall accuracy results for each epidemic (individual bars) in each location-year (H99, H00, and so on). For each location-year, the epidemics with the highest, lowest, and an intermediate level of accuracy were selected for display in Figure 1. 
be nondamaging and 11 correctly model to be damaging) (Fig. 4; Table 1). All six incorrect outcomes were false positives (observed nondamaging epidemic that was declared by the model to be damaging).

The decision aid website was functional every growing season starting in 2006 (and, as a demonstration using only the experiment station site, from 2000 to 2005). Website operation was generally uninterrupted but there were occasional outages of individual weather stations. Most of the outages were due to failure of communications equipment and, when the data stream was reestablished, the compromised weather data file was repaired with measurements from the affected site. In rare instances, the outages were due to malfunction of sensors attached to the weather station, and the weather data set had to be repaired with measurements taken at the nearest site having complete data.

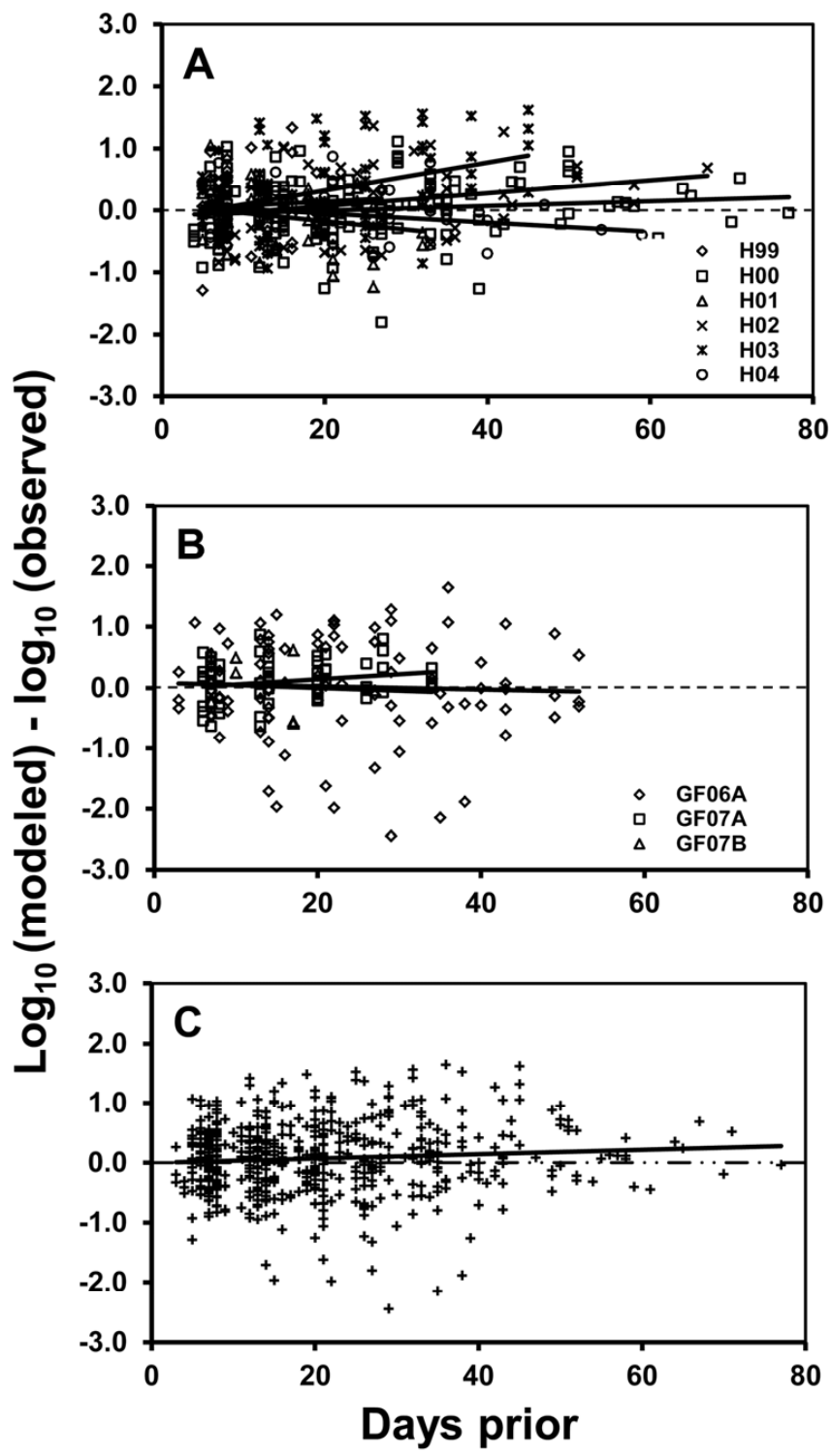

Fig. 3. Deviances of modeled disease severities from observed disease severities ( $\log _{10}$ modeled minus $\log _{10}$ observed) for epidemics of perennial ryegrass stem rust modeled with STEMRUST_G. For each location-year, each deviance is plotted against the interval in days between initialization date for the model run and date of the observation for which the deviance is computed. Solid lines show linear regression of deviance versus time interval for each location-year. Dot-dash line is reference for zero deviation. A, Deviances for epidemics observed in plots at experiment farm in 1999 through 2004. B, Deviances for epidemics observed in large-scale demonstration plots in grower fields in 2006 and 2007. C, Deviances for all epidemics.
Use of the online stem rust decision-aid totaled 12,688 model runs during the years 2005 to 2013. Number of runs for these years was $2,200,1,850,950,1,400,1,500,600,1,100,700$, and 2,400 , respectively, thus averaging 1,400 runs per year.

The large-plot trials of the decision aid conducted in grower fields compared results of applying fungicides according to the decision aid ("model-informed") versus according to standard practice. Various levels of epidemic severity occurred among the

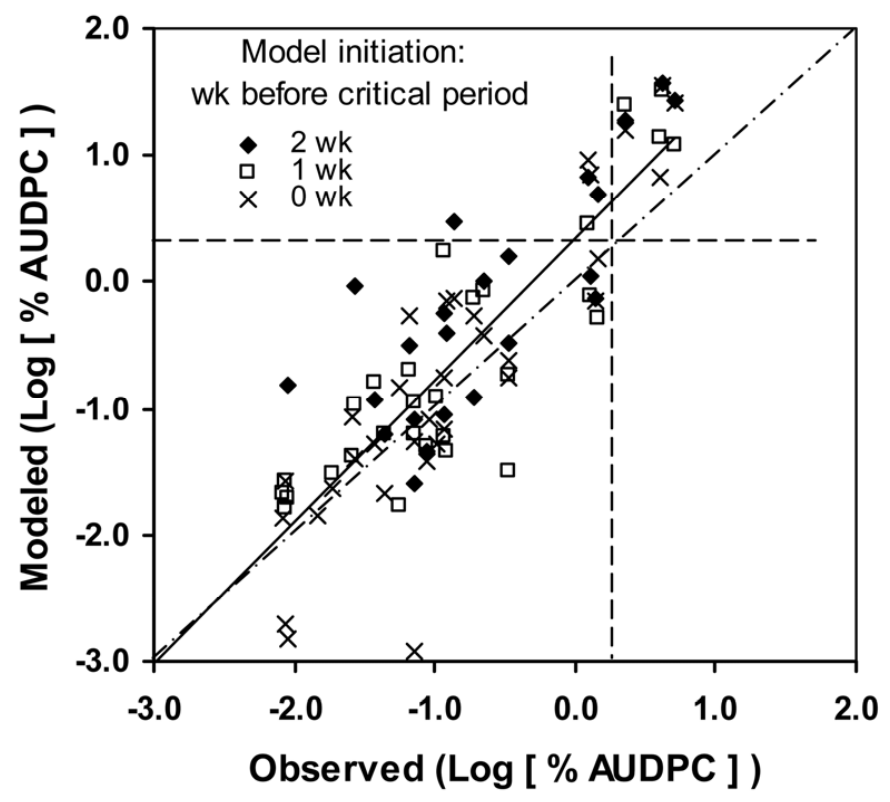

Fig. 4. Comparison of modeled and observed area under the disease progress curve (AUDPC) computed for the yield-critical time window midway between anthesis and harvest (21). AUDPC is expressed as percentage of healthy area duration, plotted as $\log _{10}$ values. For each epidemic, modeled AUDPCs were determined in runs initialized at the beginning of the yield-critical time window and at 1 and 2 weeks prior to that date if observed disease was present then. Dashed lines partition the graph area into zones less than or greater than the threshold for AUDPC (2\%) that causes yield loss (21). The solid line is the linear regression of modeled versus observed and the dot-dash line is reference for equality.

TABLE 1. Contingency table for the number of perennial ryegrass stem rust epidemics above or below the damage threshold, according to modeled or observed area under the disease progress curve (AUDPC) ${ }^{\mathrm{a}}$

\begin{tabular}{lcrc}
\hline & & \multicolumn{2}{c}{ Observed AUDPC } \\
\cline { 3 - 4 } Initialization $^{\mathrm{b}}$ & Modeled AUDPC & $\leq 2 \%$ & $>2 \%$ \\
\hline 2 weeks & $\leq 2 \%$ & 17 & 0 \\
& $>2 \%$ & 3 & 3 \\
\multirow{2}{*}{ week } & $\leq 2 \%$ & 24 & 0 \\
& $>2 \%$ & 1 & 4 \\
0 week & $\leq 2 \%$ & 28 & 0 \\
& $>2 \%$ & 2 & 4 \\
Combined & $\leq 2 \%$ & 69 & 0 \\
& $>2 \%$ & 6 & 11 \\
\hline
\end{tabular}

a Thirty-four epidemics across nine location-years in Pacific Northwest of the United States. Not all epidemics had observed disease present at 2- and 1 -week initiation dates. The threshold for yield loss to the seed crop was previously determined (21) to be AUDPC $=2 \%$ of healthy area duration for the 20-day period midway between anthesis and swathing of the crop. Modeled AUPDC was calculated from output of STEMRUST_G run with inputs of on-site weather data and fungicide application and initialized with the observed disease severity value at the indicated time.

b Model initialization date (weeks before start of critical period). Combined $=$ all model runs. 
10 location-years (Table 2). Across these varying conditions, there were two location-years showing a statistically significant increase in seed yield for the model-informed treatment over the standard treatment. In the other eight location years, there was no significant yield difference between the standard and the modelinformed treatments. For six location-years, fewer fungicide applications were made in the model-informed treatment than in the standard treatment, resulting in lower production costs. There were no cases with more fungicide applications in the modelinformed treatment than in the standard treatment, and there were no cases in which there was significantly less yield in the modelinformed treatment. The average economic advantage for modelinformed management across the 10 location years (reduced fungicide cost or improved yield) was estimated at $\$ 18$ per ha.

\section{DISCUSSION}

STEMRUST_G was created for two types of use: (i) as a heuristic tool to illustrate the development of ryegrass stem rust epidemics under various conditions of weather and fungicide input and (ii) as a decision aid for fungicide application to manage stem rust in ryegrass seed crops in the Pacific Northwest of the United States. The model was validated for these purposes by comparing observed disease severities during epidemics with the corresponding severity estimates produced by the model when run with an observed initial severity value, weather data from the site, and fungicide application inputs. The criteria for acceptability were (i) graphs of modeled disease progress curve are generally congruent with plotted disease severity observations; (ii) negligible overall bias (average deviation between modeled and observed severities $\approx 0$ ); (iii) modeled severity is accurate in at least $75 \%$ of the comparisons, where accuracy is defined as the modeled value being within twice the $95 \%$ CI of the observed value within \pm 1 day; and (iv) use of the model as a decision aid for fungicide application is beneficial in disease management. In addition to the validation testing described in this article, STEMRUST_G had been subjected to "multistage validation" $(28,29)$ during its development: several of the individual submodels, including infection probability, latent period duration, plant growth dynamics, and fungicide effects on infection and sporulation, had previously been developed and independently validated (17-22).

We conclude that STEMRUST_G meets the criterion for subjective validation (29) based on graphical results. It produces disease progress curves that generally conform to the observed development of stem rust severity in ryegrass seed crops, as illustrated in most of the epidemics shown in Figure 1. The epidemics for which the model was least accurate (Fig. 1, center column of graphs) included some examples (Fig. 1E and Q) in which the modeled disease progress curve was parallel to the observed severities but over- or underestimated them. This pattern could be produced by deficiencies in the model or by inaccuracy of the observed disease severity value used to initialize the model run. Thus, the poor fit seen in Figure 1Q (model run initiated with the observed value from day 140) would be judged a good representation when the model is initiated with the value observed

TABLE 2. Economic differences between standard and decision aid-informed management of stem rust in perennial ryegrass seed crops ${ }^{\mathrm{a}}$

\begin{tabular}{|c|c|c|c|c|c|c|c|c|c|}
\hline \multirow[b]{2}{*}{ Year } & \multirow[b]{2}{*}{ Variety } & \multirow[b]{2}{*}{ Field } & \multirow[b]{2}{*}{ Severity $(\%)^{\mathrm{b}}$} & \multirow[b]{2}{*}{ Treatment } & \multicolumn{2}{|c|}{ Seed yield } & \multicolumn{2}{|c|}{ Fungicide sprays } & \multirow[b]{2}{*}{ Advantage $(\$)^{\mathrm{f}}$} \\
\hline & & & & & $\mathrm{kg} / \mathrm{ha}^{\mathrm{c}}$ & Value $(\$)^{\mathrm{d}}$ & Number & $\$ / h^{e}$ & \\
\hline \multirow[t]{6}{*}{2004} & Extreme & BV_04 & 60 & Standard & 1,995 & $\ldots$ & 3 & 38 & $\ldots$ \\
\hline & $\ldots$ & $\ldots$ & $\ldots$ & Decision aid & 2,188 & $\ldots$ & 2 & 25 & $\ldots$ \\
\hline & $\ldots$ & $\ldots$ & $\ldots$ & Difference & 193 & 57 & -1 & -13 & 70 \\
\hline & Paragon & PT_04 & 85 & Standard & 1,787 & $\ldots$ & 3 & 38 & $\ldots$ \\
\hline & $\ldots$ & $\ldots$ & $\ldots$ & Decision aid & 1,740 & $\ldots$ & 3 & 38 & $\ldots$ \\
\hline & $\ldots$ & $\ldots$ & $\ldots$ & Difference & ns & 0 & 0 & 0 & 0 \\
\hline \multirow[t]{6}{*}{2005} & Paragon & TG_05 & 58 & Standard & 1,360 & $\ldots$ & 2 & 25 & $\ldots$ \\
\hline & $\ldots$ & $\ldots$ & $\ldots$ & Decision aid & 1,482 & $\ldots$ & 1 & 13 & $\ldots$ \\
\hline & $\ldots$ & $\ldots$ & $\ldots$ & Difference & ns & 0 & -1 & -13 & 13 \\
\hline & Stellar & WB_05 & 73 & Standard & 2,155 & $\ldots$ & 3 & 38 & $\ldots$ \\
\hline & $\ldots$ & $\ldots$ & $\ldots$ & Decision aid & 2,090 & $\ldots$ & 3 & 38 & $\ldots$ \\
\hline & $\ldots$ & $\ldots$ & $\ldots$ & Difference & ns & 0 & 0 & 0 & 0 \\
\hline \multirow[t]{6}{*}{2006} & OS & SP_06 & 44 & Standard & 2,867 & $\ldots$ & 2 & 25 & $\ldots$ \\
\hline & $\ldots$ & $\ldots$ & $\ldots$ & Decision aid & 2,894 & $\ldots$ & 2 & 25 & $\ldots$ \\
\hline & $\ldots$ & $\ldots$ & $\ldots$ & Difference & ns & 0 & 0 & 0 & 0 \\
\hline & Margarita & MC_06 & Trace & Standard & 1,505 & $\ldots$ & 2 & 25 & $\ldots$ \\
\hline & $\ldots$ & $\ldots$ & $\ldots$ & Decision aid & 1,332 & $\ldots$ & 1 & 13 & $\ldots$ \\
\hline & $\ldots$ & $\ldots$ & $\ldots$ & Difference & ns & 0 & -1 & -13 & 13 \\
\hline \multirow[t]{6}{*}{2007} & VNS & S1_07 & 72 & Standard & 2,250 & $\ldots$ & 2 & 25 & $\ldots$ \\
\hline & $\ldots$ & $\ldots$ & $\ldots$ & Decision aid & 2,404 & $\ldots$ & 2 & 25 & $\ldots$ \\
\hline & $\ldots$ & $\ldots$ & $\ldots$ & Difference & ns & 46 & 0 & 0 & 46 \\
\hline & VNS & SL_07 & $<1$ & Standard & 1,533 & $\ldots$ & 1 & 13 & $\ldots$ \\
\hline & $\ldots$ & $\ldots$ & $\ldots$ & Decision aid & 1,450 & $\ldots$ & 0 & 0 & $\ldots$ \\
\hline & $\ldots$ & $\ldots$ & $\ldots$ & Difference & ns & 9 & -1 & -13 & 13 \\
\hline \multirow[t]{6}{*}{2008} & LS 3000 & S2_08 & 2 & Standard & 2,063 & $\ldots$ & 1 & 13 & $\ldots$ \\
\hline & $\ldots$ & $\ldots$ & $\ldots$ & Decision aid & 2,115 & $\ldots$ & 0 & 0 & $\ldots$ \\
\hline & $\ldots$ & $\ldots$ & $\ldots$ & Difference & ns & 0 & -1 & -13 & 13 \\
\hline & Silver Dollar & ST_08 & 0 & Standard & 2,304 & $\ldots$ & 1 & 13 & $\ldots$ \\
\hline & $\ldots$ & $\ldots$ & $\ldots$ & Decision aid & 2,285 & $\ldots$ & 0 & 0 & $\ldots$ \\
\hline & $\ldots$ & $\ldots$ & $\ldots$ & Difference & ns & 0 & -1 & -13 & 13 \\
\hline \multirow[t]{3}{*}{ Average } & $\ldots$ & $\ldots$ & $\ldots$ & Standard & 1,982 & $\ldots$ & 2.0 & $\ldots$ & $\ldots$ \\
\hline & $\ldots$ & $\ldots$ & $\ldots$ & Decision aid & 1,998 & $\ldots$ & 1.4 & $\ldots$ & $\ldots$ \\
\hline & $\ldots$ & $\ldots$ & $\ldots$ & Difference & 16 & $\ldots$ & -0.6 & $\ldots$ & 18 \\
\hline
\end{tabular}

\footnotetext{
${ }^{a}$ Fungicide applied as decided by grower (standard) or as determined by decision aid.

b Ambient stem rust severity measured on 1 July in a nonsprayed plot at the location.

${ }^{c}$ Differences shown if statistically significant as determined by linear contrast, $P=0.05$; ns $=$ not significant.

${ }^{\mathrm{d}}$ Perennial ryegrass seed at $\$ 0.30 / \mathrm{kg}$.

e One fungicide application $=\$ 12.75 /$ ha, including application cost.

${ }^{\mathrm{f}}$ Economic advantage due to decision aid = (income benefit of significant yield increase) + (reduction in cost of fungicide)
} 
on day 148 or any subsequent day. A similar comment applies to the epidemic shown in Figure 1E. We note also some cases of poor representation by the model at high disease severities (Fig. $1 \mathrm{~L}$ and $\mathrm{U})$, as has been reported to sometimes occur in other plant disease models $(4,6,30)$. The practical impact of errors at very high disease severity would be minimal for the decision-aid, because it is unlikely that any management input would be able to save a crop if the rust epidemic were permitted to become so severe.

By statistical measures also, the model appears to be suitable for the intended uses. The overall bias of modeled disease estimates is negligible, at $0.07 \log _{10}$ units (equivalent to a 1.15 fold difference). The bias is slightly larger when the initializationto-comparison time interval is long, and bias approaches 0 when that time interval is $\approx 5$ days (Fig. $3 \mathrm{C}$ ). There is, however, a large variance in the size of the errors. Therefore, the accuracy of the estimates within epidemics and location-years is of interest. Our rationale in defining an acceptable range of accuracy (twice the $95 \%$ CI of the observed value) was that we could not expect the model to be any more accurate than the observations used in the validation (i.e., the $95 \% \mathrm{CI}$ ), and that an additional twofold range for error and a time window of \pm 1 day would not be so great as to render the model unsuitable for its uses. We found that $81 \%$ of comparisons across all epidemics and $85 \%$ of those with initialization-to-comparison times $\leq 14$ days were accurate. This outcome meets our stated goal of $75 \%$ accuracy. Although the model was not uniformly accurate for all experiments, we conclude that it is likely to produce a useful estimate of disease severity at a given time during an epidemic. We saw also that, in $85 \%$ of cases, the model initiated up to 2 weeks before the beginning of the damage critical period produced an accurate categorization of critical-period AUDPC as damaging or nondamaging (Fig. 4; Table 1). This means that the model should be useful in making management decisions as a crop approaches its yield-critical stage. All AUDPC modeling errors we observed were false positives. This error pattern would sometimes lead to fungicide application when it is not needed but would be unlikely to risk disease damage due to an incorrect "don't spray" decision. That is, the model is slightly conservative with respect to risk of disease control failure.

Some steps were taken toward model qualification (28) (i.e., validation for conditions beyond those used in its development). Compared with the datasets used to create and train the model (25), the validation datasets (used in this article) represented a larger number of individual years and, thus a larger range of weather patterns. The overall bias (0.07) of this more comprehensive database was similar to that of the training data set $(0.04)$. Further, inclusion of three off-site location-year data sets (grower fields GF06A and so on) in the validation testing extended the validation domain to other locations within the region and to a small number of additional cultivars beyond 'Morningstar', the one used in model development (compare Fig. 3A and B). Among cultivars currently grown in the region, none is resistant to stem rust, and 'Morningstar' is in the middle of the somewhat narrow overall range of susceptibilities. The additional experiments conducted in grower fields for the purpose of assessing the decision aid (Table 2) added eight additional cultivars to the validation domain.

One important complicating aspect of assessing model performance is the difficulty in obtaining true values of actual ("observed") stem rust severity when sampling a crop. This difficulty derives from several factors. Stem rust epidemics are typically focal in their development, particularly when they originate in small, scattered groups of pustules of the overwintering pathogen, as they do in perennial ryegrass stands in the Pacific Northwest of the United States. The spatial distribution of the disease remains aggregated to a considerable degree, at least until late in the epidemic, so that the true disease severity may be misrepresented in the samples taken, particularly at low disease incidence. Another complicating factor is the very dense canopy of a fully developed crop, which makes it impractical to inspect all plant tissue within a sampling quadrat. Therefore, the fullcanopy rust population in a quadrat has to be estimated from what is observed in the visible layer of the canopy sample (25). This estimation unavoidably introduces more error. In addition, when stem rust severity is great, the host leaves senesce or die prematurely and it is difficult to distinguish living from dead pustules. For all of these reasons, the $95 \% \mathrm{CI}$ of the observations is fairly large, and any one value of disease severity (though averaged across 5 to 10 quadrats) may be somewhat distant from the true mean disease severity on that date. In testing the model, we conducted multiple model runs with each epidemic dataset, each run starting on one of the observation dates. We compared all subsequent observations in that dataset with the modeled values from the run initiated on that date (see Figure $4 \mathrm{~B}$ in literature citation 25). If the initial observed value for any run is erroneous (e.g., due to sampling error), the modeled disease progress curve will poorly estimate the subsequent observed data points in that run if they are true values and the model is an accurate representation of disease increase. By conducting model runs initiated on each observation date for each epidemic, we intended to average out the effects of such possible observation error on model evaluation. In their validation of a wheat rust model, Rossi et al. (26) noted that there is a likelihood of error due to sampling aggregated disease at low severities. Rykiel (28) pointed out that observed data are not an infallible standard against which to compare model performance, and this consideration is likely applicable to the STEMRUST_G validation effort.

These difficulties of disease assessment can affect the use of the model as a decision aid. With respect to spatial aggregation of disease, the disease model was built, calibrated, and tested with data obtained by averaging samples taken without regard to disease aggregation. A disease manager using the decision aid may base fungicide application decisions on average disease severity in the field (in whatever way that is assessed). Alternatively the manager could run the model twice, first with the initializing "observed severity" measured within a disease focus, then with the observation taken outside the focus, and make a decision about fungicide application based on the prevalence and size of foci. Another difficulty, that of distinguishing living from recently killed pustules, can be an important problem in observations made within a few days after fungicide application. STEMRUST_G models the population of living pustules, and a scouting value that mistakenly includes recently killed pustules together with living pustules thus overestimates the disease severity. When the inflated value is used to initialize a model run, it will cause the model to overestimate subsequent disease. Conversely, if the inflated value is used as an observation in evaluating a model run initialized on an earlier date, the model output will appear to underestimate this severity value. We addressed this problem by including the modeled fungicide-killed pustules as part of the total disease in the STEMRUST_G output for the first 5 days after a fungicide application.

A decision aid can be useful if it provides information that is not otherwise readily accessible to the decision maker (9). The stem rust decision aid creates an estimate of the number of latent infections (which are invisible during most of latent period), and uses the estimate in deciding whether the size of the rust population warrants fungicide application to avoid crop damage. The complex effects of fungicides on infection, pustule development, and viable spore production are estimated. The model calculates current disease level based on the last available scouting data and the intervening weather conditions, permitting the disease manager to scout at less frequent time intervals. The practical value of this model-derived information depends both on how accurate it is and on what degree of accuracy is needed to achieve an improve- 
ment in disease management compared with standard practices. We attempted to obtain a pragmatic assessment of the decision aid's value by conducting large-plot trials in grower fields. Results from these experiments indicate that the decision aid is useful for disease management. There were instances of reduced pesticide use and some instances of increased seed yield through the use of the decision aid. The decision aid was most useful in years of low to moderate disease severity (Table 2), when it permitted the disease manager to delay or forgo fungicide application. In years of severe epidemic development, the number of fungicide applications suggested by the decision aid will probably be the same as that of standard practice, although the timing of fungicide application may be somewhat better optimized with use of the decision aid. This improved timing is suggested by instances where the decision aid gave improved yield with the same number of fungicide applications as the standard practice (Table 2). Pragmatic performance of the decision aid is favored by the fact that there are multiple time points when the fungicide application decision can be made, allowing the disease manager to repeatedly run the model with new information and review the decision $(9,24)$. Thus, the model need only be acceptably accurate over the time interval between field scoutings. Conversely, if the user has confidence in the model, the decision aid can be used to adjust the frequency of scouting according to whether or not the current disease level modeled from the previous observation is near the action threshold.

As a tool for illustrating stem rust epidemic dynamics, STEMRUST_G implemented on the described website can be used to explore the expected course of stem rust epidemics under various scenarios of weather conditions and fungicide application programs. Archived weather data can be used for visualizing epidemic development during years known by the user to have been particularly favorable or unfavorable for epidemics. We did not assess directly the type of use, heuristic or pragmatic, to which the decision aid website was put. Anecdotal information (unpublished observations) suggests that most of the use is by extension service and private-sector crop advisors rather than by individual growers. Such pass-along value has probably increased over time, as trained decision aid users operate the model at appropriate times and disseminate results via other means of communication (9). There was no clear trend in usage (number of model runs per year) over the 9 years we logged traffic on the website. This large year-to-year variation in decision-aid use could be attributed to several possible causes. Not all runs for research and development use were correctly identified and removed for most of this period. Over time, the number of weather stations operating decreased from 12 stations in earlier years to only 3 , which could affect the number of users who would have a weather station located near their geographic area of interest. Also, a large year-to-year variation in the prevalence and severity of stem rust in the region could affect interest, although it is not clear whether interest would be greater in a severe epidemic year (when there is a substantial risk of loss but a degree of certainty about the need for fungicides) or in a mild epidemic year, in which uncertainty might prompt more uses.

The utility of the decision aid could be improved by several modifications. In its current form, the decision aid is not a disease forecaster; it simulates disease (visible and latent) from a given initial severity up to the most recent date for which weather data is available. It would not be difficult to implement a disease forecast by STEMRUST_G based on a weather forecast, and this modification in the decision aid website is planned. Another development which would improve the applicability of the decision aid is the planned implementation of an estimator for weather conditions (temperature, rainfall, and leaf wetness) for geographical locations not served by a physical weather station. The website at which STEMRUST_G is deployed (uspest.org/wea), has a utility to create "virtual weather stations" (VWS). The online user can click in a map to place this VWS; then, the system creates estimated hourly weather data for running numerous plant disease models that are part of the overall system. These estimated weather data files are created with information from nearby observing weather stations. Estimation is done with distance weighting, in an elevation-weather parameter regression approach. This method often performs well for temperature and dewpoint but less well for relative humidity, rainfall, and leaf wetness (unpublished). Implementing the VWS with STEMRUST_G will require conversion of standard-observation weather data (as used by uspest.org) into an estimate of the canopy-level data used by STEMRUST_G. Previous work identified some approaches to this conversion that appear to be adequate (23). The qualified domain of STEMRUST_G and the associated decision aid could be improved by testing on a larger diversity of cultivars, as well as with more fungicides and doses. The model currently is parameterized only for full labeled doses of the two major fungicide classes (triazoles and strobilurins) for stem rust in grasses. Experiments similar to those done in the development of this model (25) but with lower doses or other fungicides would allow the model to be reparameterized as needed. Expansion of the geographical domain also would require additional validation. Finally, STEMRUST_G might serve as the basis of an epidemic model for stem rust in wheat or barley, after obtaining necessary parameterizing data from experiments quantifying such processes as infection efficiency, latent period, pustule dynamics, and fungicide effects on the rust population in those hosts.

\section{ACKNOWLEDGMENTS}

The use of trade, firm, or corporation names in this publication is for the information and convenience of the reader. Such use does not constitute an official endorsement or approval by the United States Department of Agriculture or the Agricultural Research Service of any product or service to the exclusion of others that may be suitable.

\section{LITERATURE CITED}

1. Amorim, L., Berger, R. D., Bergamin Filho, A., Hau, B., Weber, G. E., Bacchi, L. M. A., Vale, F. X. R., and Silva, M. B. 1995. A simulation model to describe epidemics of rust of Phaseolus beans. II. Validation. Phytopathology 85:722-727.

2. Andrade-Piedra, J. L., Forbes, G. A., Shtienberg, D, Grunwald, N. J., Chacon, M. G., Taipe, M. V., . Hijmans, R. J., and Fry, W. E. 2005. Qualification of a plant disease simulation model: Performance of the LATEBLIGHT model across a broad range of environments. Phytopathology 95:1412-1422.

3. Andrade-Piedra, J. L., Hijmans, R. J., Forbes, G. A., Fry, W. E., and Nelson, R. J. 2005. Simulation of potato late blight in the Andes. I: Modification and parameterization of the LATEBLIGHT model. Phytopathology 95:1191-1199.

4. Andrade-Piedra, J. L., Hijmans, R. J., Juarez, H. S., Forbes, G. A., Shtienberg, D., and Fry, W. E. 2005. Simulation of potato late blight in the Andes. II: Validation of the LATEBLIGHT model. Phytopathology 95:1200-1208.

5. Bajwa, W. I., Coop, L., and Kogan, M. 2003. Integrated pest management (IPM) and internet-based information delivery systems. Neotrop. Entomol. 32:373-383.

6. Berger, R. D., Hau, B., Weber, G. E., Bacchi, L. M. A., Bergamin Filho, A., and Amorim, L. 1995. A simulation model to describe epidemics of rust of Phaseolus beans I. Development of the model and sensitivity analysis. Phytopathology 85:715-721.

7. Calonec, A., Cartolaro, P., Naulin, J. M., Bailey, D., and Langlais, M. 2008. A host-pathogen simulation model: Powdery mildew of grapevine. Plant Pathol. 57:493-508.

8. Flack, J. A., Zielke, P. A., Pavkov, A., and Kovel-Jarboe, P. 1988. Integrating technologies in extension programs. Pages 481-486 in: Proc. 2nd Int. Conf. Comput. Agric. Ext. Programs, Vol. II. F. S. Zazueta and A. B. Bottcher, eds. University of Florida, Lake Buenavista.

9. Gent, D. H., Mahaffee, W. F., McRoberts, N., and Pfender, W. F. 2013. The use and role of predictive systems in disease management. Annu. Rev. Phytopathol. 51:267-289.

10. Gleason, M. L., Duttweiler, K. B., Batzer, J. C., Taylor, S. E., Sentelhas, P. C., Boffino Almeida Monteiro, J. E., and Gillespie, T. J. 2008. 
Obtaining weather data for input to crop disease-warning systems: Leaf wetness duration as a case study. Sci. Agric. 65:76-87.

11. Goodall, D. W. 1972. Building and testing ecosystem models. Pages 173194 in: Mathematical Models in Ecology. J. N. Jeffers, ed. Blackwell, Oxford.

12. Jones, V. P., Brunner, J. F., Grove, G. G., Petit, B., Tangren, G. V., and Jones, W. E. 2010. A web-based decision support system to enhance IPM programs in Washington tree fruit. Pest Management Sci. 66:587-595.

13. Krause, R. A., Massie, L. B., and Hyre, R. A. 1975. Blitecast, a computerized forecast of late blight of potato. Plant Dis. Rep. 59:95-98.

14. Kropff, M., Teng, P., and Rabbinge, R. 1995. The challenge of linking pest and crop models. Agric. Syst. 49:413-434.

15. Paveley, N. D. 1997. Determinants of fungicide spray decisions for wheat. Pestic. Sci. 49:379-388.

16. Pitblado, R.E. 1988. Development of a weather-timed fungicide program for field tomatoes. Can. J. Plant Pathol. 10:371.

17. Pfender, W. F. 2001. A temperature-based model for latent period duration in stem rust of perennial ryegrass and tall fescue. Phytopathology 91:111116.

18. Pfender, W. F. 2003. Prediction of stem rust infection favorability, by means of degree-hour wetness duration, for perennial ryegrass seed crops. Phytopathology 93:467-477.

19. Pfender, W. 2004. Role of phenology in host susceptibility and withinplant spread of stem rust during reproductive development of perennial ryegrass. Phytopathology 94:308-316.

20. Pfender, W. F. 2006. Interaction of fungicide physical modes of action and plant phenology in control of stem rust of perennial ryegrass grown for seed. Plant Dis. 90:1225-1232.

21. Pfender, W. 2009. A damage function for stem rust of perennial ryegrass seed crops. Phytopathology 99:498-505.

22. Pfender, W. F., and Eynard, J. 2009. Field assessment of a model for fungicide effects on intraplant spread of stem rust in perennial ryegrass seed crops. Phytopathology 99:696-703.

23. Pfender, W. F., Gent, D. H., and Mahaffee, W. F. 2011. Sensitivity of disease management decision aids to temperature input errors associated with sampling interval and out-of-canopy sensor placement. Plant Dis. 96:726-736.

24. Pfender, W. F., Gent, D. H., Mahaffee, W. F., Coop, L. B., and Fox, A. D. 2011. Decision aids for multiple-decision disease management as affected by weather input errors. Phytopathology 101:644-653.
25. Pfender, W. F., and Upper, D. 2015. A simulation model for epidemics of stem rust in ryegrass seed crops. Phytopathology 105:45-56.

26. Rossi, V., Racca, P., Giosue, S., Pancaldi, D., and Alberti, I. 1997. A simulation model for the development of brown rust epidemics in winter wheat. Eur. J. Plant Pathol. 103:453-465.

27. Russo, J. M. 1999. Weather forecasting for IPM. Pages 453-479 in: Emerging Technologies for Integrated Pest Management: Concepts, Research, and Implementation. G. G. Kennedy and T. B. Sutton, eds. American Phytopathological Society Press, St. Paul, MN.

28. Rykiel, E. J. 1996. Testing ecological models: The meaning of validation. Ecol. Model. 90:229-244.

29. Sargent, R. G. 1984. A tutorial on verification and validation of simulation models. Pages 114-121 in: Proc. 1984 Winter Simulation Conf. S. Sheppard, U. Pooch, and C. Pedgen, eds. IEEE Press, Piscataway, NJ.

30. Savary, S., Willoquet, L., and Teng, P. S. 1997. Modelling sheath blight epidemics on rice tillers. Agric. Syst. 55:359-384.

31. Skelsey, P., Kessel, G. J. T., Rossing, W. A. H., and van der Werf, W. 2009. Parameterization and evaluation of a spatiotemporal model of the potato late blight pathosystem. Phytopathology 99:290-300.

32. Spoden, G. J., and Seely, M. W. 1986. Using automated weather stations in sugarbeet management. ASA-CSSA-SSSA Abstr. Presented Pap. 78th Annu. Meet. New Orleans, LA.

33. Stone, N. D., Coulson, R. N., Frisbie, R. E., and Loh, D. K. 1986. Expert systems in entomology: Three approaches to decision making. Bull. Entomol. Soc. Am. 32:161-166.

34. Teng, P. S., Blackie, M. J., and Close, R. C. 1980. Simulation of the barley leaf rust epidemic: Structure and validation of BARSIM-I. Agric. Syst. 5:85-103.

35. Thomas, C. S., Skinner, P. W., Fox, A. D., Greer, C. A., and Gubler, W. D. 2002. Utilization of GIS/GPS-based information technology in commercial crop decision making in California, Washington, Oregon, Idaho, and Arizona. J. Nematol. 34:200-206.

36. Waggoner, P. E., and Berger, R. D. 1987. Defoliation, disease, and growth. Phytopathology 77:393-398.

37. Welty, R. E., and Azevedo, M. D. 1994. Application of propiconazole in management of stem rust in perennial ryegrass grown for seed. Plant Dis. 78:236-240

38. Wharton, P. S., Kirk, W. W., Baker, K. M., and Duynslager, L. 2008. A Web-based interactive system for risk management of potato late blight in Michigan. Comput. Electron. Agric. 61:136-148. 